\title{
Proteomic analysis provides integrated insight into mechanisms of Turnip mosaic virus long distance movement in Brassica rapa
}

\author{
C. LIU ${ }^{1}$, G.-S. SUN ${ }^{2}$, R.-J. ZHANG ${ }^{1}$, S.-W. LV ${ }^{1}$, L. GAO ${ }^{1}$, L.-W. GAO ${ }^{1}$, T.-K. LIU ${ }^{1}$, D. XIAO ${ }^{1}$, X.-L. HOU ${ }^{1}$, \\ and C.-W. ZHANG ${ }^{1 *}$
}

State Key Laboratory of Crop Genetics and Germplasm Enhancement, College of Horticulture, Nanjing Agricultural University, Nanjing, Jiangsu, 210095, P.R. China ${ }^{1}$

Zhenjiang Institute of Agricultural Sciences in Hilly Area of Jiangsu Province,

Jurong, Jiangsu, 212400, P.R. China ${ }^{2}$

\begin{abstract}
In non-heading Chinese cabbage, the yield relies mostly on the health of leaves, which can be heavily impacted by turnip mosaic virus (TuMV). The virions or viral ribonucleoprotein complexes are transported through the phloem and xylem. Plasmodesmata are indispensable because they traverse cell walls and connect companion cells, allowing virus particles long distance movement. However, which complexes and genes participate in this process is still unknown. Plants can activate defense mechanisms and apply disease resistance genes to respond to pathogen attacks. In this study, we collected the stems and petioles infected by TuMV for $7 \mathrm{~d}$ (TuMV-7), $14 \mathrm{~d}$ (TuMV-14), and $21 \mathrm{~d}$ (TuMV-21). Using isobaric tags for relative and absolute quantification-based proteomic technology, 6043 distinct proteins were identified and 323, 240, $285,203,253$, and 363 differentially expressed proteins were found in the comparable pairs of TuMV-7/control, TuMV-14/TuMV-7, TuMV-14/control, TuMV-21/TuMV-7, TuMV-21/TuMV-14, and TuMV-21/control, respectively. We performed a functional annotation analysis of all identified proteins and a functional enrichment analysis of all differentially expressed proteins. The results indicated that the long distance movement of TuMV involved many complex regulatory pathways. The respective proteins were related to those occurring in plasmodesmata and to $\mathrm{Ca}^{2+}$ transporters. Further, we also found proteins related to heat shock proteins, pathogenesis-related proteins, and proteins scavenging reactive oxygen species.
\end{abstract}

Additional key words: disease resistance, iTRAQ, non-heading Chinese cabbage, pathogenesis-related proteins, plasmodesmata.

\section{Introduction}

Brassica rapa crops (AA, $2 \mathrm{n}=20)$, such as Chinese cabbage (B. rapa ssp. pekinensis), non-heading Chinese cabbage (B. rapa ssp. chinensis), and turnip (B. rapa ssp. rapa) are well-known for their rich nutrients, short growth periods, and adaptability.

Potyviruses make up the largest genus of plant viruses and affect more than $50 \%$ of crops. Turnip mosaic virus (TuMV) contains an approximately 10-kb RNA genome.
Electron microscopy shows that the viral particles are nonenveloped, approximately $680-900 \mathrm{~nm}$ in length and $11-15 \mathrm{~nm}$ in diameter, and form flexuous rods (Wan et al. 2015a). TuMV has become the second most prevalent virus in fields, after cucumber mosaic virus.

One priority in breeding has been the development of disease-resistant agricultural cultivars. Many genes related to disease resistance have been identified since Jenner

Submitted 17 August 2017, last revision 9 June 2018, accepted 14 June 2018.

Abbreviations: APX - ascorbate peroxidase; DREPP - developmentally-regulated PM polypeptide; ER - endoplasmic reticulum; HSPs - heat shock proteins; iTRAQ - isobaric tags for relative and absolute quantification; MP - movement protein; PATL - patellin; PCaP plasma membrane-associated cation binding protein; PD - plasmodesmata; PGIPs - PG-inhibiting proteins; PGs - endopolygalacturonases; PM - plasma membrane; PME - pectin methylesterase; PRs - pathogenesis-related proteins; ROS - reactive oxygen species; RT-PCR - reverse transcription PCR; sHSPs - small heat shock proteins; TuMV - turnip mosaic virus.

Acknowledgements: The work was supported by the grants from the Fundamental Research Funds for the Central University (KYZ201826), the Nature Science Foundation of Jiangsu Province (BK20141364), and three new agricultural engineering program of Jiangsu, SXGC[2016]315. The first two authors contributed equally to this work.

* Corresponding author; fax: (+86) 25 84395266, e-mail: changweizh@njau.edu.cn 
et al. (2002) observed the 12 TuMV groups, for which some resistance loci exist in Brassica crops. Walsh et al. (1999) identified TuRBO1 and TuRBO2 and Jenner et al. (2002) identified TuRBO4 and TuRB05. Other identified genes include TuRB01b, ConTR01 and retr01 (Rusholme et al. 2007), Rnt1 (Fujiwara et al. 2011), and retr02 (Qian et al. 2013) in B. napus. These genes play significant roles in virus-plant interactions. The largest group is the nucleotide-binding site (NBS)-leucine-rich repeat (LRR) family including resistant $(R)$ genes against viruses (HRT, $N, R C Y 1, R x 1, R x 2$, and Sw5) (Kang et al. 2005). In addition, host defense mechanisms, with the support of chemical compounds, function to protect themselves from external invasions.

Normally, movement of viruses between cells occurs on the $3^{\text {rd }}$ day after inoculation and the systemic infection starts on the $5^{\text {th }}$ day after inoculation in the TuMVagroinfiltrated plants (Wan et al. 2015b). Cell walls protect cells from external invaders, which makes it challenging to exchange information throughout the surroundings. Plasmodesmata (PD) play an irreplaceable role in breaking the restrictions of cell walls and allowing the movement of different molecules in the xylem and phloem in which the

\section{Materials and methods}

Plants and TuMV-inoculation: Non-heading Chinese cabbage (Brassica rapa L. ssp. chinensis) cv. 49caixin as well as Nicotiana benthamiana Domin plants were grown in a cultivation chamber with a 16-h photoperiod, an irradiance of $225 \mu \mathrm{mol} \mathrm{m} \mathrm{m}^{-2} \mathrm{~s}^{-1}$, day/night temperatures of $22 / 17{ }^{\circ} \mathrm{C}$, and a relative humidity of $60-65 \%$. Six-weekold $N$. benthamiana plants were inoculated with TuMV-GFP. For this, TuMV-GFP was first introduced into Agrobacterium tumefaciens strain GV3101. The Agrobacterium was incubated in $50 \mathrm{~cm}^{3}$ of Luria-Bertani medium containing $50 \mathrm{mg} \mathrm{dm}^{-3}$ rifampicin and $50 \mathrm{mg} \mathrm{dm}^{-3}$ kanamycin and grown in a shaker at $28{ }^{\circ} \mathrm{C}$ overnight. Then, the Agrobacterium was resuspended in infiltration buffer $\left(0.25 \mathrm{~g}\right.$ of D-glucose, $5 \mathrm{~cm}^{3}$ of $500 \mathrm{mM}$ MES stock solution, $5 \mathrm{~cm}^{3}$ of $20 \mathrm{mM} \mathrm{Na}_{3} \mathrm{PO}_{4} .12 \mathrm{H}_{2} \mathrm{O}$ stock solution, $5 \mathrm{~cm}^{3}$ of $1 \mathrm{M}$ acetosyringone stock solution, and distilled water to $50 \mathrm{~cm}^{3}$ ). The infiltration buffer was adjusted to an absorbance $\mathrm{A}_{600}$ of $0.6-0.8$, incubated at room temperature for 3 to $4 \mathrm{~h}$ before infiltration and then infiltrated into leaves using a $1-\mathrm{cm}^{3}$ syringe. The nonheading Chinese cabbage was infected mechanically in the six-leaf stage. We collected $2 \mathrm{~g}$ of infected stems and petioles before inoculation and on the $7^{\text {th }}, 14^{\text {th }}$, and $21^{\text {st }}$ day after inoculation (named control, TuMV-7, TuMV-14, and TuMV-21, respectively). Then, the samples were frozen in liquid nitrogen and stored them at $-70{ }^{\circ} \mathrm{C}$ for protein separation.

Reverse transcription PCR: Total RNA was extracted long distance movement of loading and unloading occurs (Wan and Laliberte 2015). The desmotubule tightly compresses the endoplasmic reticulum (ER), creating a space between the plasma membrane (PM) and the desmotubule, called the cytoplasmic sleeve, through which various molecules, such as transcription factors, RNAs, and phytohormones, can move. The PD are used to connect sieve elements with companion cells. The movement of molecules upward and downward in the phloem may occur through these pore plasmodesmal units, which function more ubiquitously than PDs (Wan et al. 2015b). PD connect different replication complexes with viral movement and demonstrate the interaction and cooperation between protein complexes produced by viruses and plants (Lucas 2006). Coat proteins were found in the xylem, so people believed that cellular movement of these complexes is mediated by virus-encoded movement proteins (MPs), and viruses moves in the form of virions (Deng et al. 2015).

In this study, we chose the isobaric tags for relative and absolute quantification (iTRAQ) method to investigate the underlying mechanisms of the long distance movement of TuMV in non-heading Chinese cabbage.

from samples using the total RNA extraction kit (Tiangen, Beijing, China). RT-PCR was performed using genespecific primers and SYBR Green (TaKaRa, Kyoto, Japan) on an ABI PrismR 7900HT system (Applied Biosystems, Carlsbad, CA, USA) according to the instructions. The amplification procedure was as follows: pre-denaturation at $94{ }^{\circ} \mathrm{C}$ for $10 \mathrm{~s}$, followed by 40 cycles at $94{ }^{\circ} \mathrm{C}$ for $30 \mathrm{~s}$ and at $60{ }^{\circ} \mathrm{C}$ for $30 \mathrm{~s}$, and finally a melting curve was performed $\left(61\right.$ cycles at $65^{\circ} \mathrm{C}$ for $\left.10 \mathrm{~s}\right)$. The expression of $\beta$-actin was used to standardize the RNA sample for each analysis. The RT-PCR assay was performed at least three times for each experimental line. Primers were designed according to the gene sequences using Becon Designer v. 7.9 and they are listed in Table 3 Suppl. The expression is presented with the heatmap (http://www.omicshare. com/tools/index.php/Home/Soft/heatmap) and the gene sequences information can be found in our database (http://brassicadb.org/brad/).

Transmission electron microscopy: The petioles were sampled from the young leaves which were close to growing tips and the stems were sampled below the node which were close to the root. Then they were fixed with $2.5 \%(\mathrm{~m} / \mathrm{v})$ glutaraldehyde at $4{ }^{\circ} \mathrm{C}$ for $24 \mathrm{~h}$. A series of single-axis-tilt images were collected with a transmission electron microscopy (Tecnai Hitachi HT7700, Tokyo, Japan), operated at an accelerating voltage of $80 \mathrm{kV}$, and critical sample features were identified in the viewing screen of the CCD camera operating in ambient light. 
Protein extraction, digestion, and desalting: Tissue samples $(2 \mathrm{~g})$ were dissolved in $1 \mathrm{M}$ triethylammonium bicarbonate (TEAB) dissolution buffer with $0.2 \%(\mathrm{~m} / \mathrm{v})$ sodium dodecyl sulphate, broken by ultrasonic waves for $15 \mathrm{~min}$, centrifuged at $15000 \mathrm{~g}$ for $20 \mathrm{~min}$, then a fourfold volume of cold acetone containing $10 \mathrm{mM}$ dithiotreitol (DTT) was added. After $\sim 2 \mathrm{~h}$, the precipitate was collected by centrifugation at $15000 \mathrm{~g}$ and $4{ }^{\circ} \mathrm{C}$ for 20 min, mixed with $800 \mathrm{~mm}^{3}$ of cold acetone and warmed to $56{ }^{\circ} \mathrm{C}$ to break protein disulfide bonds, centrifuged again at $15000 \mathrm{~g}$ and $4{ }^{\circ} \mathrm{C}$ for $20 \mathrm{~min}$ and dried. Samples were then dissolved with $100 \mathrm{~mm}^{3}$ of TEAB buffer and finally stored at $-80{ }^{\circ} \mathrm{C}$ for later use.

The total protein content was measured using the Bradford method. For each sample, $100 \mu \mathrm{g}$ of protein was dissolved in $100 \mathrm{~mm}^{3}$ of TEAB buffer, and then diluted with $500 \mathrm{~mm}^{3}$ of $50 \mathrm{mM} \mathrm{NH} \mathrm{HCO}_{3}$. After reduction and alkylation, $2 \mu \mathrm{g}$ of trypsin was added, and then, samples were incubated at $37^{\circ} \mathrm{C}$ overnight for protein digestion. After protein digestion, an equal volume of $0.1 \%(\mathrm{v} / \mathrm{v})$ formic acid (FA) was added for acidization. Peptides were purified on Strata- $X$ (Torrance, USA) C18 columns that had been activated with methanol and then balanced by adding $1 \mathrm{~cm}^{3}$ of $0.1 \%$ FA three times, washed with $0.1 \%$ $\mathrm{FA}+5 \%(\mathrm{v} / \mathrm{v})$ acetonitrile $(\mathrm{ACN})$ twice, and eluted with $1 \mathrm{~cm}^{3}$ of $0.1 \% \mathrm{FA}+80 \% \mathrm{ACN}$. Eluted peptides were dried using a vacuum concentration pump. The dried peptide powders were redissolved with $20 \mathrm{~mm}^{3}$ of $0.5 \mathrm{M}$ TEAB for peptide labelling.

iTRAQ labeling and fractionation: Samples were labelled using an iTRAQ Reagent- 8 plex Multiplex kit (AB Sciex, Framingham, USA) according to the manufacturer's instructions. TuMV-7, TuMV-14, TuMV-21, and control were labelled with reagents 116, 117, 118, and 121 respectively. All of the labelled samples were mixed in equal amounts. Next, the labelled samples were fractionated using a high-performance liquid chromatography (Thermo DINOEX Ultimate 3000 BioRS, Waltham, USA) with a Durashell C18 column ( $5^{\circ} \mathrm{um}, 100$ $\AA, 4.6 \times 250 \mathrm{~mm})$. Finally, 12 fractions were collected.

The liquid chromatography-electrospray ionizationtandem mass spectrometry (LC-ESI-MS/MS) analysis was performed on an AB Sciex nanoLC-MS/MS (Triple TOF 5600 plus) system. Samples were chromatographed using a 90 min gradient ranging from 2 to $30 \%$ buffer $A$ [0.1\% (v/v) formic acid, $5 \%(\mathrm{v} / \mathrm{v})$ acetonitrile] and buffer B [0.1\% formic acid, $95 \%$ acetonitrile], injected directly onto a 20- $\mu \mathrm{m}$ PicoFrit emitter (New Objective, Ringoes, USA) and packed with $12 \mathrm{~cm}$ of Magic C18AQ $(3 \mu \mathrm{m}, 120$ $\AA)$ stationary phase. The MS1 spectra were collected in the range from $350-1500 \mathrm{~m} / \mathrm{z}$ for $250 \mathrm{~ms}$. The most intense 20 precursors with charge state 2 - 5 were selected for fragmentation. The MS2 spectra were collected in the range from $50-2000 \mathrm{~m} / \mathrm{z}$ for $100 \mathrm{~ms}$, and precursor ions were excluded from reselection for $15 \mathrm{~s}$.

Data analysis: The original MS/MS file data were submitted to ProteinPilot v.4.5 (https://sciex.com/ products/software/proteinpilot-software) for analysis. The protein identification was employed against Uniprot Chlorella B. rapa (41 720 items, updated in Aug. 2016) for a database search. The parameters were set as follows: the instrument was a TripleTOF 5600; iTRAQ quantification and cysteine were modified with iodoacetamide; biological modifications were selected as ID foci; trypsin digestion; and the quantitation, bias correction and background correction were checked for protein quantification and normalization. The false discovery rate calculation used an automatic decoy database search strategy with the Proteomics System Performance Evaluation Pipeline software (integrated into the ProteinPilot software) algorithm. Only proteins with at least one unique peptide and an unused value more than 1.3 were considered for further analysis. Some identified peptides were excluded from the quantitative analysis for one of the following reasons: 1) peaks corresponding to the iTRAQ labels were not detected; 2) the identified peptide had a low identification confidence values; 3) the peptide was claimed by more than one protein; 4) the signal-tonoise ratio for the peptide was too low; or 5) the combined feature probability for the peptide was less than $30 \%$, because it was a semitryptic peptide, missing an iTRAQ reagent label, had a low probability modification, or had a large delta mass. For protein abundance ratios measured using iTRAQ after normalization, a 1.5-fold change and a $P$-value less than 0.05 were used as the thresholds to identify significant changes.

Bioinformatics: To determine the biological and functional properties of the identified proteins, their protein sequences were mapped using gene ontology $(G O)$ terms (http://geneontology.org/). A homology search was first performed for all of the identified sequences using a localized NCBI BLASTP program against the NCBI $n r$ animal database. The e-value was set to less than 1e-5, and the best hit for each query sequence was used for matching $G O$ terms. The $G O$ term matching was performed with blast2go 4.5 pipeline5. Clusters of orthologous groups of proteins (http://www.ncbi.nlm.nih.gov/COG/) were employed for the functional annotation of genes from new genomes and for research into genome evolution. To identify candidate biomarkers, we employed a hypergeometric test to perform $G O$ enrichment and $K E G G$ pathway enrichment (http://www.genome.jp/kegg/), and each protein sequence, as well as functional information, was provided by UniProt databases (http://www. uniprot.org/). All other figures in this paper were drawn using $R$ language (http://www.r-project.org/). 


\section{Results}

To ensure that the plants were infected with TuMV, we used transmission electron microscopy to investigate the ultrastructural particles of TuMV (Fig. 1). Chloroplasts with starch grains were spread around the cell walls (Fig. 1A,B). The viral replication complexes in plants have different forms. We found that round-like viral structures, containing an axis and radial arms, only exist in the infected samples (Fig. 1C,D). The structures in the petioles indicated that viral replication and transport occurred in the phloem and xylem. To complete the long distance movement, the virus must distribute the virions to new distant sites through phloem cells and sieve elements, thus invading the whole plant (Hipper et al. 2014).

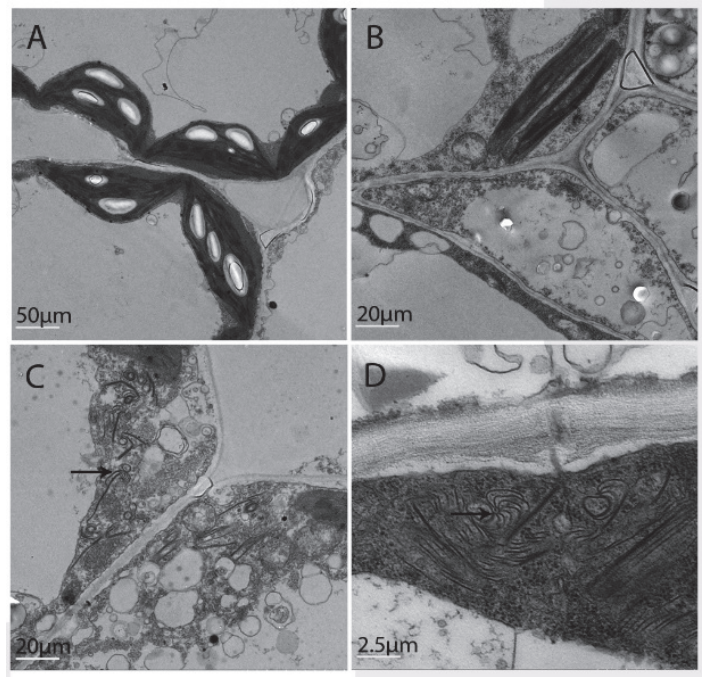

Fig. 1. Ultrastructure of Chinese cabbage cells. $A$ and $B$ are the control plants $C$ and $D$ are the TuMV-infected plants. $A$ and $C$ are the stems, $B$ and $D$ are petioles. The scale bars in $A, B, C$, and $D$ are $50,20,20$, and $2.5 \mu \mathrm{m}$, respectively.

After summarizing the iTRAQ results, 415772 spectra were obtained and approximately 164219 MS spectra were identified, which was in accordance with the known spectra and the identification rate was $39.50 \%$. ProteinPilot software was employed to characterize the number of identified peptides (see the identification criteria under Materials and methods). In total, 40478 peptides were screened, from which 6043 proteins were identified and $5322(88.07 \%)$ proteins contained at least two unique peptides. The identified proteins coverage from 0 to $10 \%$ was $28.62 \%$, the coverage $\geq 20 \%$ was $50.07 \%$ and the average coverage was $25.64 \%$ (Fig. $2 A$ ). The peptide lengths of identified proteins ranged mainly from 8 aa to 15 aa, with the most common length being 11 aa, and the average length being 14.46 (Fig. 2B). The confidence percentage of matching amino acids was $\geq$ $95 \%$. According to the criteria for defining differentially expressed proteins (fold change ratio $\geq 1.5$ and $P \leq 0.05$ ), the number of down-regulated and up-regulated proteins are shown in Table 1. This indicates that the TuMV infection changed the proteins to a certain degree, and that the iTRAQ results were reliable and worthy of being investigated further.

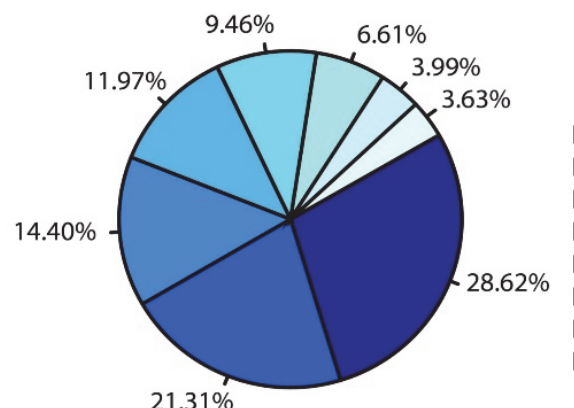

A

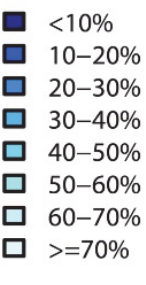

DISTRIBUTION OF PEPTIDES LENGTH

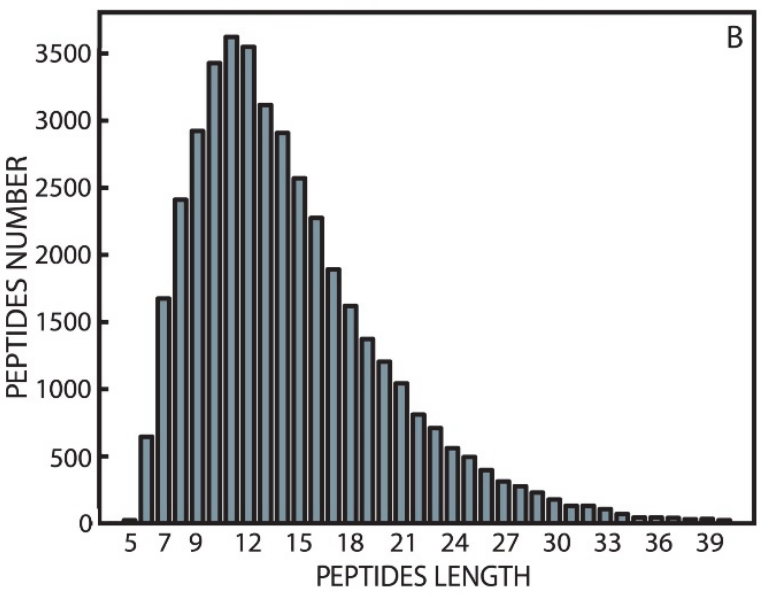

Fig. 2. Protein identification and function classification of identified proteins. $A$ - Pie chart of protein coverage (peptides with confidence $\geq 95 \%$ ). $B$ - Peptides length distribution.

The identified proteins were sub-categorized into 54 hierarchically-structured $G O$ classifications, including 28 in biological process, 11 in cellular component, and 13 in molecular function (Fig. 3). Specifically, 'metabolic processes' (14.6 $8 \%$ ) and 'cellular processes' (15.18\%) (biological process), 'cell part' $(25.42 \%)$ and 'cell' $(24.53 \%)$ (cellular component), 'catalytic activity' (40.24\%) and 'binding' (43.67\%) (molecular function) were highly represented. All of the proteins were also subcategorized into $24 C O G$ classifications, and the $R$ (general function prediction only), $\mathrm{O}$ (posttranslational modification, protein turnover, chaperones) were highly represented (Fig. 4). All 4419 proteins were subcategorized into $257 \mathrm{KEGG}$ classifications. The top 10 pathway annotations for the identified proteins are shown in Table 1 Suppl.

Most differentially expressed proteins, both up- and down-regulated, were enriched in 'metabolic process and cellular process' (biological process), 'cell and cell part' 


\section{LIU et al.}

Table 1 . The number of differentially expressed proteins identified in our experiments.

\begin{tabular}{lcllrrr}
\hline Sample pairs & $\begin{array}{l}\text { TuMV-7/ } \\
\text { control }\end{array}$ & $\begin{array}{l}\text { TuMV-14/ } \\
\text { TuMV-7 }\end{array}$ & $\begin{array}{l}\text { TuMV-14/ } \\
\text { control }\end{array}$ & $\begin{array}{l}\text { TuMV-21/ } \\
\text { TuMV-7 }\end{array}$ & $\begin{array}{l}\text { TuMV-21/ } \\
\text { TuMV-14 }\end{array}$ & $\begin{array}{l}\text { TuMV-21/ } \\
\text { control }\end{array}$ \\
\hline Quantified & 5941 & 5942 & 5934 & 5942 & 5940 & 5939 \\
Up-regulated & 180 & 127 & 161 & 83 & 104 & 186 \\
Down-regulated & 143 & 113 & 124 & 120 & 149 & 176 \\
Total different & 323 & 240 & 285 & 203 & 253 & 362 \\
\hline
\end{tabular}

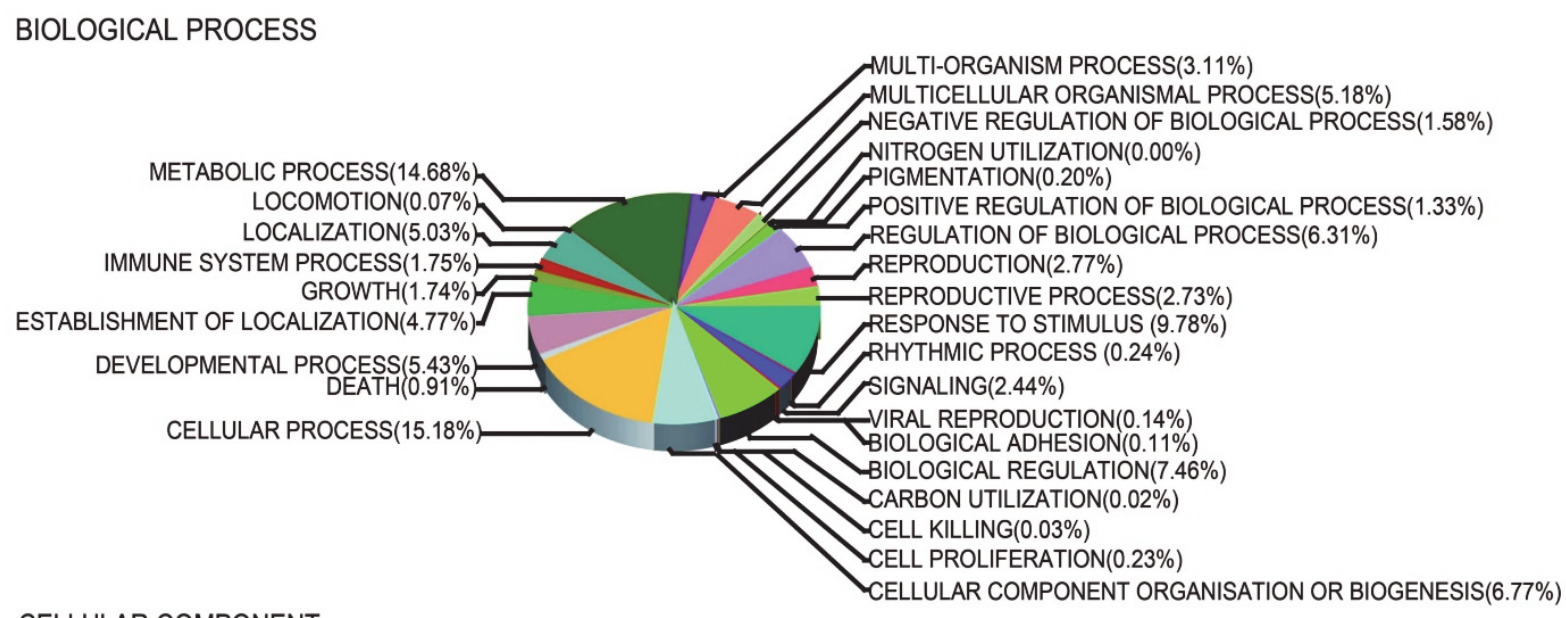

CELLULAR COMPONENT

MEMBRANE-ENCLOSED LUMEN $(2.57 \%)$ MACROMOLECULAR COMPLEX $(5.90 \%)$ EXTRACELLULAR REGIN PART $(0.28 \%)$ EXTRACELLULAR REGIN $(4.65 \%)$

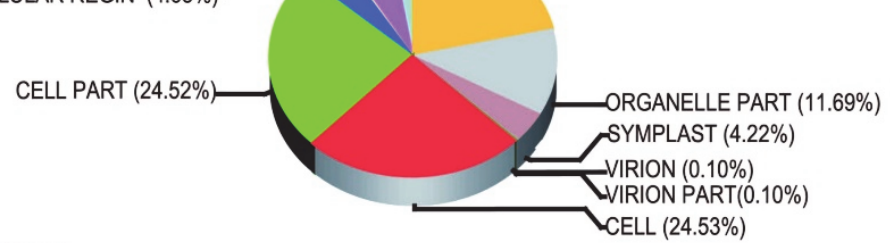

\section{MOLECULAR FUNCTION}

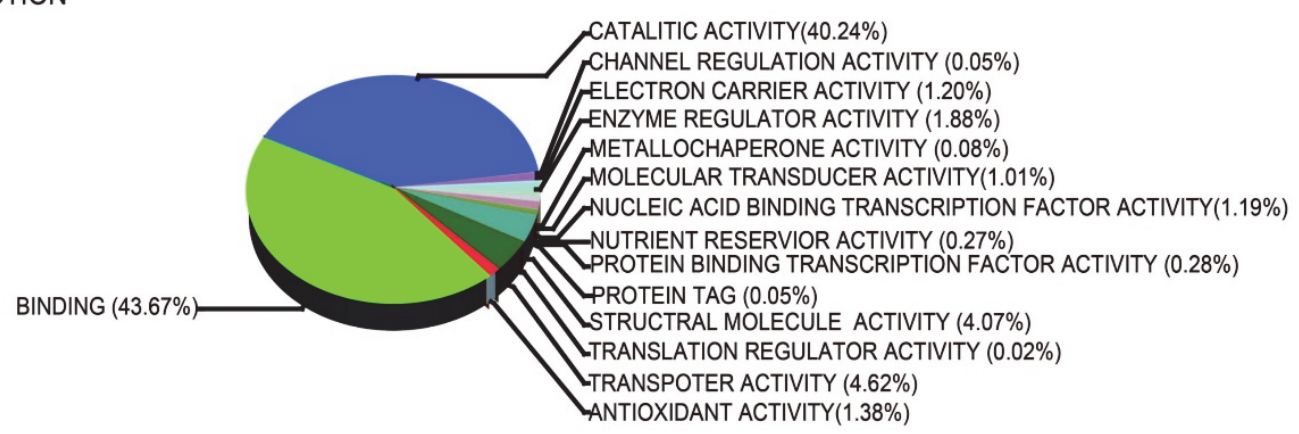

Fig. 3. Gene ontology classification of all identified proteins.

(cellular component) and 'binding and catalytic activity' (molecular function) (Fig. 1 Suppl. - Fig. 6 Suppl.). KEGG pathway enrichment analyses were used to uncover the enriched pathways of the significantly altered proteins. Significantly enriched pathways were identified using a $P$-value based on a hypergeometric distribution (Fig. 1 Suppl. - Fig. 6 Suppl.). In summary, we found that
'Metabolic pathway' and 'Biosynthesis of secondary metabolites' had the greatest percentage in all of the different pairwise comparisons. There were $41.3 \%$ (102), $46.67 \%$ (84), $44.66 \%$ (92), $37.33 \%$ (56), $42.16 \%$ (78), $44.15 \%$ (117) proteins in 'metabolic pathway' and $28.74 \%$ (71), $27.78 \%$ (50), $28.16 \%$ (58), $21.33 \%$ (32), $27.57 \%(51), 30.57 \%(81)$ in 'biosynthesis of secondary 
metabolites' in TuMV-7/control, TuMV-14/TuMV-7, TuMV-14/control, TuMV-21/TuMV-7, TuMV-21/
TuMV-14, and TuMV-21/control, respectively.

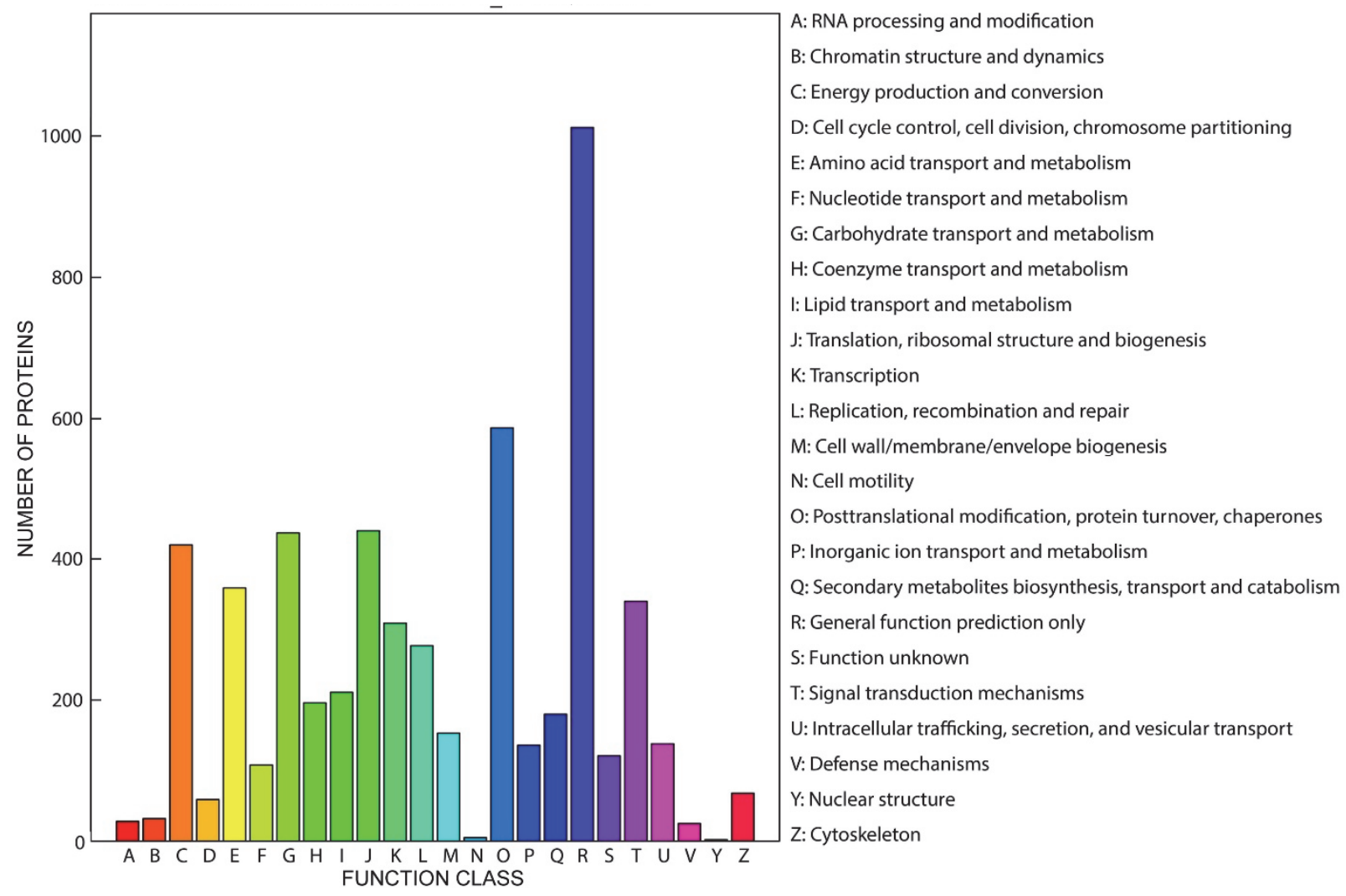

Fig. 4. $C O G$ classification of all identified proteins.

We investigated the proteins significantly expressed in TuMV long distance movement and resistance, such as connected with PD, plasma membrane (PM; Lee 2015), $\mathrm{Ca}^{2+}$ signalling (Vosolsobě et al. 2017), chitinase (Patel and Goyal 2015), and ROS (Agrawal et al. 2003, Zhang et al. 2008 ). In this study, 7 proteins (4 up- and 3 downregulated) were found in ' $\mathrm{Ca}^{2+}$ signalling pathway', 130 proteins in 'oxidative phosphorylation', 88 proteins in 'glutathione metabolism' and 56 proteins in 'ascorbate and aldarate metabolism' in TuMV-7/control, TuMV-14/

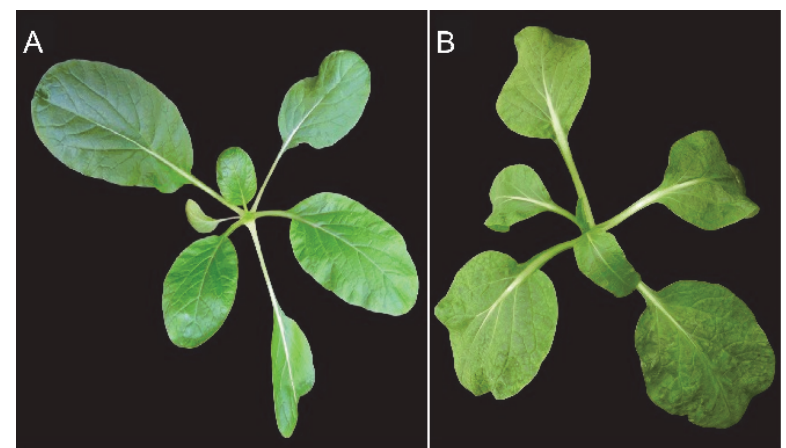

Fig. 5. Symptoms of infected non-heading Chinese cabbage on the $21^{\text {th }}$ day after infection $(A$ - non-infected, $B$ - infected).
TuMV-7, TuMV-14/control, TuMV-21/TuMV-7, TuMV21/TuMV-14 and TuMV-21/control, respectively. Moreover, 96, 75, 74, 74, 86, 93 PD proteins and 98, 77, 75, 78, 88, 96 PM proteins were enriched, respectively, in these comparisons. Additionally, plenty of proteins were found in the vacuole, symplast, cell wall, and apoplast. For 'molecular function', most proteins were distributed among 'peroxidase activity', 'oxidoreductase activity', 'hydrolase activity', 'glutathione transferase activity', and 'chitin binding'. Additionally, 'response to stimulus', 'response to stress', 'hydrogen peroxide metabolic process' and 'oxygen and reactive oxygen species metabolic processes' were highly represented within the major category 'biological process'.

In Fig. 5, the symptoms on plants $21 \mathrm{~d}$ after inoculation are shown. In this study, we chose some differentially expressed genes related to virus resistance and long distance movement (Zhang et al. 2008, Patel and Goyal 2017, Vosolsobě et al. 2017) and ran RT-PCR (http://brassicadb.org/brad/)(Table 2 Suppl.). The relative expression (Fig. 6) showed that, in general, the up and down regulation of genes was consistent with the iTRAQ results, further confirming the resistance effect. 


\section{Discussion}

Plasmodesmata serve as the gateways for most plant viruses that pirate and modify the channel to complete the virions spread using their movement proteins. The movement protein (MP) of TMV moves between cells and influences the size-based exclusion limit of PD (Ueki and Citovsky 2011). We found that some host proteins, including pectin methylesterase (PME) (Bra001547, PME3) and Arabidopsis patellin (PATL) family proteins (Bra008012, PATL1), interact with MPs, having certain effects on the long distance movement (Chen et al. 2000, Peiro et al. 2014). PMEs are cell wall-associated proteins which regulate viral unloading from the phloem (Chen and Citovsky 2003). PMEs can interact with the MP of TMV during the virus long distance movement (Chen et al. 2000). Reduced content of PME can cause significant delay of TMV systemic infection (Chen and Citovsky 2003), which fits our RT-PCR results. PATL1 is a member of the phosphatidylinositol transfer proteins family and plays key role in vesicle/membrane trafficking during cell expansion or maturation (Peterman et al. 2004, 2006). The expression of PATL1 increased after inoculation in our study. PATLs can restrain movements of alfalfa mosaic virus (AMV) through cells by targeting MPs to $\mathrm{PD}$, resulting in a decrease in the infection's foci sizes (Deom et al. 1987). Meanwhile, viral RNA expression increase in PATL knockouts (Peiro et al. 2014). Though the

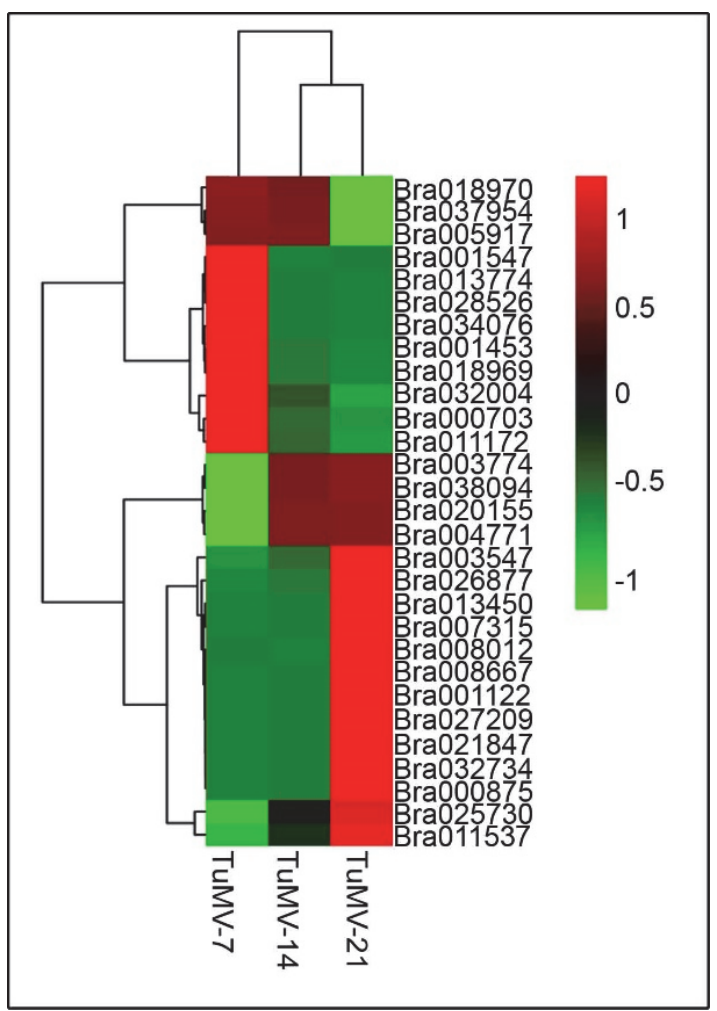

Fig. 6. Heatmap of relative expression level of genes related to TuMV resistance. The red colour represents up-regulated genes and the green represents down-regulated genes. expressions of host proteins changed in our study, it was unsure whether the host proteins were involved in the long distance movement.

Developmentally-regulated PM polypeptide (DREPP) proteins are specific proteins that bind the PM and calcium (Yamada et al. 2015). DREPP proteins are specific to plants, with no specific functions identified until now. We found Bra013450, which is a DREPP, Bra020155, Bra018970, Bra021847 and Bra027209, which bound calcium ions, and Bra026877, which bound calmodulin. Arabidopsis plasma membrane-associated cation binding protein 1 ( $\mathrm{PCaP} 1)$ and protein $2(\mathrm{PCaP} 2)$ can be regulated by $\mathrm{Ca}^{2+} /$ calmodulin, performing the function when the proteins are released from the PM (Vosolsobě et al. 2017). In this study, the expression of Bra013450 increased, indicating that the DREPP might be involved in the defense process. $\mathrm{Ca}^{2+}$ is considered as the second messenger and calmodulin is a $\mathrm{Ca}^{2+}$-binding protein that can be regulated in response to different stimuli. The upregulated and down-regulated expression of Bra020155, Bra018970, Bra021847, and Bra027209 showed that the $\mathrm{Ca}^{2+}$ pump balance was upset. $\mathrm{Ca}^{2+}$ regulates PM $\mathrm{H}^{+}$-ATPase (Bra011172, PMA2), which is sensitive to cell expansion and movement, as well as to $\mathrm{pH}$ changes induced by stress (Piette et al. 2011). $\mathrm{Ca}^{2+}$ act as a regulator during the interaction between PM-localized ATP-binding cassette transporter PEN3 (Bra003527, PEN3) and myrosinase (Bra037954, PEN2). The two interacting proteins are responsible for exporting glucosinolates, tryptophan-derived secondary metabolites (Campe et al. 2016). The PEN2 and PEN3 proteins also take part in microbe-associated molecular pattern-triggered callose deposition (Clay et al. 2009). The changes in expressions of Bra011172, Bra003527, and Bra037954 further confirmed the participation of $\mathrm{Ca}^{2+}$ in the immune system.

Callose, a $\beta$-glucan polysaccharide, is comprised of $\beta$-1,3-linked glucose residues and it is located at the neck region of $\mathrm{PD}$ during pathogen attack (Zavaliev et al. 2011).We found four genes that had $\beta$-1,3-glucanase activities (Bra007315, Bra008667, Bra011537, and Bra028526) and two (Bra003527 and Bra032004) that could respond to callose deposition in cell walls. Their expressions were very different, the expressions of Bra007315, Bra008667, Bra011537, and Bra003527 increased and the expressions of Bra028526 and Bra032004 decreased, but their functions remain unknown. The function of PD may be regulated by callose deposition ( $\mathrm{Xu}$ and Jackson 2010), which forms a barrier blocking the movement and thus restricts viral transmission.

Endopolygalacturonases (PGs) are cell wall-degrading enzymes (Ziaei et al. 2016). To counteract PGs activity, plants have produced PG-inhibiting proteins (PGIPs) (Bra005917). PGIPs are important defence proteins and 
belong to $R$ gene members of the extracellular LRRs, and they are located in cell walls (Di Matteo et al. 2003). It is said that overexpresing PGIPs increases resistance and reduce symptoms (Janni et al. 2008, Ferrari et al. 2003), but the expression of PGIPs decreased in our study.

Chitin serves as the energy source for some bacteria. Chitinases (Bra004771) are the enzymes to hydrolyze chitin. The genes Trichoderma chitinases confer much higher antifungal capacities than those of other chitinases (Zarinpanjeh et al. 2016). Pathogenesis-related proteins (PRs) are one of the strong weapons to fight against stresses. Chitinase (PR-3) and thaumatin-like protein (PR-5) can enhance the resistance capability (Aghazadeh et al. 2016). In this work, we identified Bra001453 (chitinase, PR-3), Bra004771 (chitinase), Bra003774 (thaumatin-like protein), and Bra025730 (pathogenesisrelated thaumatin family protein). Thaumatin-like proteins are active in destroying cell membranes and affect glucanase activity (Liu et al. 2010). PR5 proteins destroy the lipid bi-layer, creating trans-membrane pores that increase the permeability of the pathogen's PM (Vigers et al. 1992). PR-2 proteins ( $\beta$-1,3-glucanases, Bra007315) hydrolyze $\beta$-1,3-glucans which form fungal cell walls (Singh et al. 2014). PR-4 (Bra001122) contains ribonuclease activity and the expression increases under pathogen invasion and causes programmed cell death (Sugawara et al. 2016). The genes associated with PRs and chitinase showed up-regulated trend after inoculation except Bra001453, indicating TuMV-induced infection will up-regulate the resistance related genes.

Phytoalexins are the important secondary metabolites occurring under biotic stress (Hull et al. 2000). CYP83A1 (Bra032734), belonging to the glucosinolate pathway, reinforces resistance to the powdery mildew by accumulating the camalexin (Weis et al. 2013). CYP83A1 affects the biosynthesis of aliphatic and indole glucosinolates (Liu et al. 2016) which are actively released by glucohydrolases when plants facing biotic stress (Schlaeppi and Mauch 2010). The glucosidases (Bra018969 and Bra038094) and myrosinases (Bra037954) form an important self-defense system in cruciferous plants. The gene expression difference of
Bra032734, Bra018969, Bra038094, and Bra037954 as compared to control showed their involvement in the resistance.

Pathogen attack can induce the hypersensitive response, reactive oxygen species (ROS), cell death, and systemic acquired resistance (Van Breusegem and Dat 2006). ROS accumulation can result in increased callose deposits and decreased cell-to-cell transport (BenitezAlfonso and Jackson 2009). Peroxidase and ascorbate peroxidase ( $\mathrm{Bra034076}$, APX2) can turn $\mathrm{H}_{2} \mathrm{O}_{2}$ into water and $\mathrm{O}_{2}$ (Asada 1999) to reduce the oxidative damage. The expression of APX1 is low in many plant tissues normally but will be significantly up-regulated when responding to stresses (Zimmermann et al. 2004). However, APX2, a second cytosolic APX isozyme, was barely detected in many tissues which fits the expression level in this study. But APX1 and APX2 in Arabidopsis will work together to increase the plants resistance ability (Zimmermann et al. 2004, Frank et al. 2009). Furthermore, the increasing expression of glutathione S-transferase (Bra000875) protects against oxidative damage caused by excessive ROS (Sappl et al. 2009).

Heat shock proteins (Hsps) are found to be an important host factor in viral infection. HSP90s (Bra013774) are ubiquitous molecular chaperones that are involved in cell signalling (Pratt et al. 2006), protein degradation (Imai et al. 2003), hormone reception (Raman et al. 2015), as transcription factors and danger signals (Zhu et al. 2016). Small heat shock proteins (sHSPs) (Bra000703) are a major family within HSPs with functions resembling that of HSPs (Uversky et al. 2005), and sHSPs act as the type of molecular chaperone that contributes to the development of thermotolerance (Waters et al. 1996). The sHSP proteins can lead, jointly with HSP27, to cell death when defending the stress attack. We found that the expression of HSP90s (Bra013774) and sHSPs (Bra000703) in this study decreased. Blocking their function will make the cells less resistant. Some HSP90 inhibitors were proved to be helpful in virus infection (Raman et al. 2015). Phosphorylation can regulate HSPs and induce the pathogenesis-related protein genes.

\section{Conclusions}

In this project, we determined proteins associated with TuMV long distance movement and TuMV resistance with iTRAQ analysis. The results showed that proteins were enriched significantly in 'metabolic and secondary metabolites pathway', 'plant-pathogen interaction' and 'oxidative phosphorylation' groups. We found that many

proteins were connected with PD and PM, and also many proteins were involved in calcium signalling pathway. We screened 29 genes and explored their functions with RT-PCR. They all showed significantly difference in expression after TuMV inoculation. Our proteomics findings will facilitate the further study of TuMV resistance. 


\section{References}

Aghazadeh, R., Zamani, M., Motallebi, M., Moradyar, M., Moghadassi, J.Z.: Co-transformation of canola by chimeric chitinase and tlp genes towards improving resistance to Sclerotinia sclerotiorum. - World. J. Microbiol. Biotechnol. 2: 144, 2016

Agrawal, N.S., Iwahashi, H., Rakwal, R.: Importance of ascorbate peroxidases OsAPX1 and OsAPX2 in the rice pathogen response pathways and growth and reproduction revealed by their transcriptional profiling - Gene 322: 93$103,2003$.

Asada, K.: The water-water cycle in chloroplasts: scavenging of active oxygens and dissipation of excess photons. - Annu. Rev. Plant Physiol. Plant mol. Biol. 50: 601-639, 1999.

Benitez-Alfonso, Y., Jackson, D.: Redox homeostasis regulates plasmodesmal communication in Arabidopsis meristems. Plant Signal. Behav. 4: 655-659, 2009.

Campe, R., Langenbach, C., Leissing, F., Popescu, G.V., Popescu, S.C., Goellner, K., Beckers, G.J.,, Conrath, U.: $\mathrm{ABC}$ transporter PEN3/PDR8/ABCG36 interacts with calmodulin that, like PEN3, is required for Arabidopsis nonhost resistance. - New Phytol. 209: 294-306, 2016.

Chen, M.H., Citovsky, V.: Systemic movement of a tobamovirus requires host cell pectin methylesterase. - Plant J. 35: 386$392,2003$.

Chen, M.H., Sheng, J.S., Hind, G., Handa, A.K., Citovsky, V.: Interaction between the tobacco mosaic virus movement protein and host cell pectin methylesterases is required for viral cell-to-cell movement. - Embo J. 19: 913-920, 2000.

Clay, N.K., Adio, A.M., Denoux, C., Jander, G., Ausubel, F.M.: Glucosinolate metabolites required for an Arabidopsis innate immune response. - Science 323: 95-101, 2009.

Deng, P., Wu, Z., Wang, A.: The multifunctional protein CI of potyviruses plays interlinked and distinct roles in viral genome replication and intercellular movement. - Virol. J. 12: $141,2015$.

Deom, C.M.: Oliver, M.J., Beachy, R.N. The 30-kilodalton gene product of tobacco mosaic virus potentiates virus movement. - Science 237: 389-394, 1987.

Di Matteo, A., Federici, L., Mattei, B., Salvi, G., Johnson, K.A., Savino, C., De Lorenzo, G., Tsernoglou, D., Cervone, F.: The crystal structure of polygalacturonase-inhibiting protein (PGIP), a leucine-rich repeat protein involved in plant defense. - Proc. nat. Acad. Sci. USA 100: 10124-10128, 2003.

Ferrari, S., Vairo, D., Ausubel, F.M., Cervone, F., De Lorenzo, G.: Tandemly duplicated Arabidopsis genes that encode polygalacturonase-inhibiting proteins are regulated coordinately by different signal transduction pathways in response to fungal infection. - Plant Cell 15: 93-106, 2003.

Frank, G., Pressman, E., Ophir, R., Althan, L., Shaked, R., Freedman, M., Shen, S., Firon, N.: Transcriptional profiling of maturing tomato (Solanum lycopersicum L.) microspores reveals the involvement of heat shock proteins, ROS scavengers, hormones, and sugars in the heat stress response. - J. exp. Bot. 60: 3891-3908, 2009.

Fujiwara, A., Inukai, T., Kim, B.M., Masuta, C.: Combinations of a host resistance gene and the CI gene of turnip mosaic virus differentially regulate symptom expression in Brassica rapa cultivars. - Arch. Virol. 156: 1575-1581, 2011

Hipper, C., Monsion, B., Bortolamiol-Becet, D., Ziegler-Graff, V., Brault, V.: Formation of virions is strictly required for turnip yellows virus long-distance movement in plants. - J. gen. Virol. 95: 496-505, 2014.

Hull, A.K., Vij, R., Celenza, J.L.: Arabidopsis cytochrome P450 that catalyze the first step of tryptophan-dependent indole-3acetic acid biosynthesis. - Proc. nat. Acad. Sci. USA 97: 2379-2384, 2000.

Imai, J., Maruya, M., Yashiroda, H., Yahara, I., Tanaka, K.: The molecular chaperone Hsp90 plays a role in the assembly and maintenance of the 26S proteasom. - Embo J. 22: 3557-3567, 2003.

Janni, M., Sella, L., Favaron, F., Blechl, A.E., Lorenzo, D.G., D'Ovidio, R.: The expression of a bean PGIP in transgenic wheat confers increased resistance to the fungal pathogen Bipolaris sorokiniana. - Mol. Plant Microbe Interact. 21: 171-177, 2008.

Jenner, C.E., Wang, X., Ponz, F., Walsh, J.A.: A fitness cost for Turnip mosaic virus to overcome host resistance. - Virus Res. 86: 1-6, 2002.

Kang, B.C., Yeam, I., Jahn, M.M.: Genetics of plant virus resistance. - Annu. Rev. Phytopathol. 43: 581-621, 2005.

Lee, J.Y. : Plasmodesmata: a signaling hub at the cellular boundary - Curr. Opin. Plant Biol. 27: 133-140, 2015.

Liu, J.J., Sturrock, R., Ekramoddoullah, A.K.: The superfamily of thaumatin-like proteins: its origin, evolution, and expression towards biological function. - Plant Cell Rep. 29: 419-436, 2010

Liu, S., Bartnikas, L.M., Volko, S.M., Ausubel, F.M., Tang, D.: Mutation of the glucosinolate biosynthesis enzyme cytochrome $\mathrm{P}_{450} 83 \mathrm{~A} 1$ monooxygenase increases camalexin accumulation and powdery mildew resistance. - Front. Plant Sci. 7: 227, 2016.

Lucas, W.J.: Plant viral movement proteins: agents for cell-to-cell trafficking of viral genomes. - Virology 344: 169-184, 2006.

Patel, S., Goyal, A.: Chitin and chitinase: role in pathogenicity, allergenicity and health - Int. J. Biol. Macromol. 97: 331-338, 2017.

Peiro, A., Izquierdo-Garcia, A.C., Angel Sanchez-Navarro, J.A., Pallas, V., Miguel, J.M., Aparicio, F.: Patellins 3 and 6, two members of the plant patellin family, interact with the movement protein of alfalfa mosaic virus and interfere with viral movement. - Mol. Plant Pathol. 15: 881-891, 2014.

Peterman, T.K., Ohol, Y.M., McReynolds, L.J., Luna, E.J.: Patellin1, a novel Sec14-like protein, localizes to the cell plate and binds phosphoinositides. - Plant Physiol. 136: 3080-3094, 2004.

Peterman, T.K., Sequeira, A.S., Samia, J.A., Lunde, E.E.: Molecular cloning and characterization of patellin1, a novel sec14-related protein, from zucchini (Cucurbita pepo). - J. Plant Physiol. 163: 1150-1158, 2006.

Piette, A.S., Derua, R., Waelkens, E., Boutry, M., Duby, G.: A phosphorylation in the C-terminal auto-inhibitory domain of the plantpPlasma membrane $\mathrm{H}+$-ATPase activates the enzyme with no requirement for regulatory 14-3-3 proteins. - J. biol. Chem. 286: 18474-18482, 2011.

Pratt, W.B., Morishima, Y., Murphy, M., Harrell, M.: Chaperoning of glucocorticoid receptors. - Handbook exp. Pharmacol. 172: 111-138, 2006.

Qian, W., Zhang, S., Zhang, S., Li, F., Zhang, H., Wu, J., Wang, X., Walsh, J.A., Sun, R.: Mapping and candidate-gene screening of the novel Turnip mosaic virus resistance gene retr02 in Chinese cabbage (Brassica rapa L.). - Theor. appl. 
Genet. 126: 179-188, 2013

Raman, S., Singh, M., Tatu, U., Suguna, K.: First structural view of a peptide interacting with the nucleotide binding domain of heat shock protein 90. - Sci. Rep. 5: 17015, 2015.

Rusholme, R.L., Higgins, E.E., Walsh, J.A., Lydiate, D.J.: Genetic control of broad-spectrum resistance to turnip mosaic virus in Brassica rapa (Chinese cabbage). - J. gen. Virol. 88: 3177-3186, 2007.

Sappl, P.G., Carroll, A.J., Clifton, R., Lister, R., Whelan, J., Millar, A.H., Singh, K.B.: The Arabidopsis glutathione transferase gene family displays complex stress regulation and co-silencing multiple genes results in altered metabolic sensitivity to oxidative stress. - Plant J. 58: 53-68, 2009.

Schlaeppi, K., Mauch, F.: Indolic secondary metabolites protect Arabidopsis from the oomycete pathogen Phytophthora brassicae. - Plant Signal. Behav. 5: 1099-1101, 2010.

Singh, D., Ambroise, A., Haicour, R., Sihachakr, D., Rajam, M.V.: Increased resistance to fungal wilts in transgenic eggplant expressing alfalfa glucanase gene. - Physiol. mol. Biol. Plants 20: 143-150, 2014.

Sugawara, T., Trifonova, E.A., Kochetov, A.V., Kanayama, Y.: Expression of an extracellular ribonuclease gene increases resistance to Cucumber mosaic virus in tobacco. - BMC Plant Biol. 16: 246, 2016.

Ueki, S., Citovsky, V.: To gate, or not to gate: regulatory mechanisms for intercellular protein transport and virus movement in plants. - Mol. Plant 4: 782-793, 2011.

Uversky, V.N., Oldfield, C.J., Dunker, A.K.: Showing your ID: intrinsic disorder as an ID for recognition, regulation and cell signaling. - J. mol. Recognit. 18: 343-384, 2005.

Van Breusegem, F., Dat, J.F.: Reactive oxygen species in plant cell death. - Plant Physiol. 141: 384-390, 2006.

Vigers, A.J., Wiedemann, S., Roberts, W.K., Legrand, M., Selitrennikoff, C.P.,Fritig, B.: Thaumatin-like pathogenesisrelated proteins are antifungal. - Plant Sci. 83: 155-161, 1992.

Vosolsobě, S., Petrášek, J., Schwarzerová, K.: Evolutionary plasticity of plasma membrane interaction in DREPP family proteins. - Biochim. biophys. Acta 1859: 686-697, 2017.

Walsh, J.A., Sharpe, A.G., Jenner, C.E., Lydiate, D.J.: Characterisation of resistance to turnip mosaic virus in oilseed rape (Brassica napus) and genetic mapping of TuRB01. - Theor. appl. Genet. 99: 1149-1154, 1999.

Wan, J., Basu, K., Mui, J., Vali, H., Zheng, H., Laliberté, J.F.: Ultrastructural characterization of turnip mosaic virusinduced cellular rearrangements reveals membrane-bound viral particles accumulating in vacuoles. - J. Virol. 89: 12441$12456,2015 \mathrm{a}$.
Wan, J., Cabanillas, D.G., Zheng, H., Laliberte, J.F.: Turnip mosaic virus moves systemically through both phloem and xylem as membrane-associated complexes. - Plant Physiol. 167: 1374-1388, $2015 b$.

Wan, J., Laliberte, J.F.: Membrane-associated virus replication complexes locate to plant conducting tubes. - Plant Signal. Behav. 10: ??-?? 2015.

Waters, E.R., Lee, G.J., Vierling, E.: Evolution, structure and function of the small heat shock proteins in plants. - J. Exp. Bot. 47: 325-338, 1996.

Weis, C., Pfeilmeier, S., Glawischnig, E., Isono, E., Pachl, F., Hahne, H., Kuster, B., Eichmann, R.,Hueckelhoven, R.: Coimmunoprecipitation-based identification of putative BAX inhibitor-1-interacting proteins involved in cell death regulation and plant-powdery mildew interactions. - Mol. Plant Pathol. 14: 791-802, 2013.

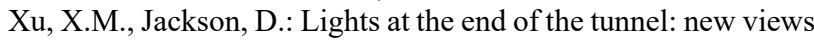
of plasmodesmal structure and function. - Curr. Opin. Plant Biol. 13: 684-692, 2010.

Yamada, N., Theerawitaya, C., Kageyama, H., Chaum, S., Takabe, T.: Expression of developmentally regulated plasma membrane polypeptide (DREPP2) in rice root tip and interaction with $\mathrm{Ca}^{2+} / \mathrm{CaM}$ complex and microtubule. Protoplasma 252: 1519-1527, 2015.

Zarinpanjeh, N., Motallebi, M., Zamani, M..R., Ziaei, M.: Enhanced resistance to Sclerotinia sclerotiorum in Brassica napus by co-expression of defensin and chimeric chitinase genes. - J. appl. Genet. 57:417-425, 2016.

Zavaliev, R., Ueki, S., Epel, B.L., Citovsky, V.: Biology of callose ( $\beta$-1,3-glucan) turnover at plasmodesmata. - Protoplasma 248: 117-130, 2011.

Zhang, W.J., Lu H., Du X.H.: The function of ascorbate peroxidases in plant resistance to oxidative stress - J. SN?? Univ.nat. Sci. 23 :113-115, 2008.

Zhu, H., Fang, X., Zhang, D., Wu, W., Shao, M., Wang, L., Gu, J.: Membrane-bound heat shock proteins facilitate the uptake of dying cells and cross-presentation of cellular antigen. Apoptosis 21: 96-109, 2016.

Ziaei, M., Motallebi, M., Zamani, M.R., Panjeh, N.Z.: Coexpression of chimeric chitinase and a polygalacturonaseinhibiting protein in transgenic canola (Brassica napus) confers enhanced resistance to Sclerotinia sclerotiorum. Biotechnol. Lett. 38: 1021-1032, 2016.

Zimmermann, P., Hirsch-Hoffmann, M., Hennig, L., Gruissem, W.: GENEVESTIGATOR. Arabidopsis microarray database and analysis toolbox. - Plant Physiol. 136: 2621-2632, 2004. 